\title{
La condicionalidad en la política de garantía de ingresos en Euskadi
}

\author{
Luis Sanzo González \\ Departamento de Empleo y Políticas Sociales, Gobierno Vasco \\ <SanzoGLu@euskadi.eus>
}

\begin{abstract}
Artikulu honetan aztertzen dira Euskadiko diru-sarrerak bermatzeko politiken inguruko eztabaidan garrantzitsuenak diren alderdiak, hau da, baldintzapeko izaeraren trataera eta gutxiengo errenten kudeaketa. Arlo honetako euskal esperientzia interesgarria da bi arrazoi nagusiengatik. Lehenik, 2008an gerturatu arren, Europako lekurik gehienetan azken batean inposatu den baldintzapeko izaera hertsitik hein handi batean urruntzen delako. Halere, gutxienezko errenten inguruko politikek ez dute ibilbide lineal bat hartu, eta hain zuzen ere, sartu izan diren aldaketek baldintzapeko izaera horrekin harremana izan dute, eta horregatik dira interesgarri azterketa honetarako bigarren arrazoi gisara. Beraz, euskal esperientziak aurkezten du, aniztasunari loturiko alderdiez gain, diru-sarrerak bermatzeko garaturiko sistema baten mantentzearen aldeko apustuaren jarraipena.
\end{abstract}

\section{GAKO-HITZAK:}

Pobrezia, diru-sarrerak bermatzeko errenta, kontraprestazioak, lan-txertaketa, eskubideak, Euskadi.
El presente artículo aborda uno de los aspectos más relevantes del debate sobre las políticas de garantía de ingresos en Euskadi: el tratamiento de la condicionalidad en el diseño y gestión de las rentas mínimas. La experiencia vasca resulta interesante en esta dimensión por dos razones principales. En primer lugar, porque se aleja en buena medida, a pesar del acercamiento posterior a 2008, de las políticas de condicionalidad estricta que han acabado imponiéndose en la mayor parte de Europa. La historia de aplicación de las políticas de rentas mínimas en Euskadi no ha resultado, sin embargo, lineal, y precisamente una parte esencial de las reformas introducidas tienen que ver con el tratamiento de la condicionalidad, siendo éste el segundo motivo por el que interesa su estudio. Así pues, la experiencia vasca se presenta en términos de diversidad, pero también de continuidad en esa apuesta por el mantenimiento de un sistema desarrollado de garantía de ingresos.

\section{PALABRAS CLAVE:}

Pobreza, renta de garantía de ingresos, contraprestaciones, inclusión laboral, derechos, Euskadi. 


\section{Introducción}

El presente artículo aborda uno de los aspectos más relevantes del debate sobre las políticas de garantía de ingresos en Euskadi: el tratamiento de la condicionalidad en el diseño y gestión de las rentas mínimas. La experiencia vasca resulta interesante en esta dimensión por dos razones principales. En primer lugar, porque se aleja en buena medida, a pesar del acercamiento posterior a 2008, de las políticas de condicionalidad estricta que han acabado imponiéndose en la mayor parte de Europa.

La percepción dominante en el entorno europeo es que la historia social y económica de la Euskadi posterior a la reconversión industrial ha resultado comparativamente exitosa, en particular en el contexto de los países del Sur; y que ello tiene, al menos en parte, alguna relación con la política social desarrollada. Sorprende, en este sentido, que una actuación alejada de los planteamientos de condicionalidad estricta, en principio asociada a un riesgo mayor de cronificación y exclusión del mercado de trabajo, haya resultado compatible con resultados sociales y económicos favorables. A esa sorpresa contribuye especialmente que Euskadi no haya seguido el difícil destino económico, marcado por el declive estructural, que ha caracterizado a la mayor parte de los territorios afectados en Europa por una drástica reducción del empleo industrial.

A pesar de una cierta continuidad, la historia de aplicación de las políticas de rentas mínimas en Euskadi no ha resultado, sin embargo, lineal, habiéndose registrado importantes cambios de enfoque a lo largo de sus ya casi treinta años de historia. Y precisamente una parte principal de las reformas introducidas tienen que ver con el tratamiento de la condicionalidad, siendo éste el segundo motivo por el que interesa su estudio. Los cambios observados se relacionan con debates sobre contraprestación, doble derecho y activación, que han dado lugar, en diversos momentos, a aproximaciones con elementos en común, pero también con sustanciales diferencias de enfoque y de conceptos.

La imagen de continuidad en la política vasca de garantía de ingresos no es, por tanto, del todo real, aunque sí tiene un fundamento último: la esencial apuesta por el mantenimiento de un sistema que garantice a la población en riesgo de pobreza y exclusión el acceso a una prestación de ingresos mínimos. En ese rasgo sí puede detectarse una trayectoria relativamente consistente en la historia de las rentas mínimas en Euskadi.

El artículo trata, en el contexto señalado, de profundizar en los aspectos relativos a la condicionalidad en la política de garantía de ingresos en Euskadi. Su objetivo principal es precisar los puntos que permiten hablar de la experiencia vasca en términos de diversidad, pero también de continuidad en esa apuesta por el mantenimiento de un sistema desarrollado de garantía de ingresos.

\section{El debate inicial sobre la contraprestación}

La estrategia de implantación de las rentas mínimas en Euskadi se concretó, a finales de los años ochenta del pasado siglo, en el Plan Integral de Lucha contra la Pobreza. Para la mayor parte de sus impulsores, el principal objetivo era establecer una prestación económica que actuara, como última red de protección, para garantizar unos ingresos mínimos a toda la población. En las condiciones de crisis ligadas a la reconversión industrial, prevenir por esa vía el incremento de las situaciones de pobreza se convirtió en un aspecto principal de la política social.

En este contexto, surgió un importante debate sobre las contrapartidas que se habían de exigir a la población beneficiaria de la nueva prestación de garantía de ingresos. Dos posiciones se perfilaron con claridad en aquel debate. La primera insistía en el principio de contraprestación. Trataba de dar respuesta a la principal preocupación de los responsables políticos en el momento del lanzamiento del Plan Integral: el temor a la consolidación de grupos dependientes del nuevo sistema de prestaciones.

Tanto la exposición de motivos del Decreto 38/89, que establecía el ingreso mínimo familiar, como la que antecedía a la Ley $2 / 1990$, que creaba el ingreso mínimo de inserción, insistían en la idea de que, con las nuevas prestaciones, no se trataba de crear una nueva clase pasiva, sino de generar, para la población estable y permanente de la Comunidad Autónoma del País Vasco, las condiciones sociales necesarias para superar la marginación. En esta línea, la Ley $2 / 1900$ afirmaba que “el ingreso mínimo de inserción no pretende crear una nueva clase pasiva, cronificando su situación, sino posibilitar su plena inserción en la vida social de Euskadi a través de la contraprestación a la que se obliga el beneficiario". En esta perspectiva, la obligación de la contraprestación venía "marcada por la voluntad de inserción que preside el ingreso, privada de la cual, se reduciría a una mera prestación de asistencia suplementaria que podría generar por sí misma nuevas formas de marginación social".

Además de consideraciones ideológicas firmemente asentadas, algunos hechos externos contribuían a reafirmar esta posición política. Debe recordarse, en este sentido, que el 'salario social' vasco era un programa innovador impulsado por una comunidad autónoma, en contra de la opinión y la voluntad del Gobierno central del Estado. Se trataba, por tanto, de una acción con un muy alto riesgo político, al que había que añadir el estrictamente económico, intrínseco a la introducción de una medida sin precedentes en la historia social española. No existían, en este sentido, experiencias previas en España respecto a lo que podría suponer el coste de un sistema de rentas mínimas como el que se pretendía implantar. La financiación del plan contra la pobreza se vinculaba además a un mecanismo 
temporal y extraordinario, definido en el Acuerdo Marco para el Desarrollo del Plan Extraordinario 'Euskadi en la Europa del 93', suscrito el 29 de mayo de 1989. Los aspectos financieros de la actuación sólo estaban temporalmente asegurados, por tanto.

El temor ante la posibilidad de consolidar un nuevo grupo social con dependencia de las prestaciones, con evidentes implicaciones económicas, condicionó por tanto el punto de vista de la parte política dispuesta a impulsar el Plan. De ahí su apuesta por la condicionalidad, la contraprestación entonces perfilada, un mecanismo que permitía disponer de instrumentos para hacer frente a una posible cronificación en la prestación. Se trababa, sin embargo, de una condicionalidad que venía acompañada de medidas de promoción, con la pretensión de potenciar lo que se definía como el tercer nivel del plan, los programas de inserción que debían hacer posible la reintegración en la sociedad. Aunque estos programas se planteaban, en general, para facilitar el acceso al trabajo, también preveían actuaciones de intervención, promoción y protección social. Se planteaba, por tanto, un proyecto de inserción tanto social como laboral.

En el lado opuesto de la balanza, se encontraban quienes desde algunos sectores técnicos de las distintas administraciones vascas defendían la necesidad de establecer un derecho no condicionado. El peculiar modelo de desarrollo del Plan Integral de Lucha contra la Pobreza, con fuerte participación técnica, dio voz a este grupo en la fase de diseño de la nueva política.

En parte de este grupo técnico, destacaba un planteamiento de oposición a la concepción dominante en el recientemente aprobado Revenu Minimum d'Insertion (RMI) en Francia. La principal crítica se centraba en la idea de que el derecho a la prestación económica era inseparable del compromiso de participación en acciones de inserción, un planteamiento que exigía, por tanto, la aceptación previa del compromiso de inserción para acceder a la protección económica. La ley francesa de diciembre de 1988 establecía, en este sentido, que "cualquier persona residente en Francia cuyos recursos [...] no alcanzan la cuantía del ingreso mínimo [...] y que se compromete a participar en las acciones o actividades determinadas con ella, necesarias para su integración social o profesional, tiene derecho, en las condiciones previstas en la presente ley, a un ingreso mínimo de inserción”.

En las iniciativas jurídicas de 1989 y 1990, la influencia de este grupo fue importante a la hora de matizar, en dos sentidos, la política de contraprestaciones. Un primer aspecto consistió en una nítida separación entre acceso a la prestación de garantía y contraprestación. De esta forma, el principio de condicionalidad se situó fuera de la definición esencial del objeto central de la actuación y de los requisitos de acceso, y quedó asociado en exclusiva a las obligaciones establecidas para mantener la prestación de ingresos mínimos. En términos de la Ley 2/1990, la obligación de contraprestación quedó así concretada: “prestar por escrito su compromiso para realizar aquellas contraprestaciones que, en su caso, se determinen [...] con el fin de incentivar la integración social de los beneficiarios de la prestación”. La contraprestación no aparecía, por tanto, como precondición o requisito para acceder a la prestación. No obstante, el incumplimiento de la obligación sí podía fundamentar procesos de suspensión o extinción de la prestación.

Una segunda implicación asociada, claramente consolidada en la Ley 2/1990, era la afirmación expresa del derecho al ingreso mínimo, presentado en la exposición de motivos como "un importante derecho social”. La nueva ley señalaba, en este sentido, que su objeto es "la creación [...] de una prestación, denominada ingreso mínimo de inserción, dirigida a la integración social de aquellas personas que carezcan de los recursos económicos necesarios para atender a las necesidades básicas de la vida". El derecho quedaba además desligado de límites temporales, con una prestación susceptible de mantenerse "mientras subsistan las causas que motivaron su concesión".

La nueva legislación se caracterizaba igualmente por un claro rechazo al principio de contraprestación laboral. Se formulaba una oposición explícita a la participación obligada en trabajos de utilidad pública o social como condición para el mantenimiento de las prestaciones. De esta forma, la Ley establecía que las contraprestaciones "se definirán preferentemente en el ámbito de la Formación Profesional y Ocupacional, quedando, en todo caso, excluidas las prestaciones de naturaleza laboral”.

Esta aproximación reflejaba la solución técnica que se fue perfilando para resolver, en la fase inicial de lanzamiento de las rentas mínimas en Euskadi, las contradicciones planteadas entre partidarios y oponentes del principio de contraprestación. Se trató, en gran medida, del acoplamiento del objetivo de inserción que procedía del Revenu Minimum d'Insertion francesa con una afirmación del derecho a una garantía de recursos inspirado en lo que se percibía había sido la aproximación original del Estado del bienestar (en la terminología actual, en esta última perspectiva, una forma de renta garantizada únicamente vinculada a la demostración de la insuficiencia de recursos).

\section{La Ley contra la Exclusión Social: doble derecho y estímulos al empleo}

El acercamiento en los planteamientos de las dos partes que protagonizaron el debate inicial caracteriza una evolución posterior que acabaría concretándose en la Ley 12/1998 contra la Exclusión Social, llamada a consolidar en términos financieros ordinarios la política vasca de garantía de ingresos. 
La nueva normativa se caracteriza por dos hitos en la aproximación a la condicionalidad: por una parte, la introducción del modelo de doble derecho a una prestación de garantía y a un apoyo individualizado para la inserción, concretado en el convenio de inserción; por otra, la introducción del sistema de estímulos al empleo.

\subsection{El doble derecho}

En su configuración básica, la Ley contra la Exclusión Social de 1998 trataba de regular los instrumentos de carácter social y las prestaciones económicas que se consideraban necesarias para prevenir el riesgo de exclusión personal, social y laboral; así como para contribuir a la inserción de quienes carecieran de los recursos personales, sociales o económicos suficientes para desarrollar una vida independiente. En la práctica, esta aproximación implicaba la renuncia al principio de contraprestación como condición asociada al acceso a las ayudas. Apostaba, en cambio, por el doble derecho a una renta mínima $y$, de manera complementaria, a una acción pública a favor de la inserción de las personas en riesgo de exclusión.

En la dimensión económica, la ley de 1988 consolidaba como derecho subjetivo la política de garantía de ingresos. También desvinculaba mucho más claramente la prestación de ingreso mínimo de la acción para la inserción. La Ley definía así el ingreso mínimo de inserción como "una prestación periódica de naturaleza económica dirigida a cubrir las necesidades de aquellas personas que carezcan de recursos económicos suficientes para hacer frente a los gastos básicos para la supervivencia”.

En la dimensión relativa a la inserción, el acceso al empleo y a los programas de inserción se configuraba como un nuevo derecho, y no como una contrapartida por el acceso a la prestación económica. En esta aproximación, los convenios de inserción se perfilaban como los instrumentos destinados a hacer realidad el derecho a la inserción. Estos convenios se definían como documentos-programa, en los que las partes intervinientes (el sector público, a través de los ayuntamientos, y las personas destinatarias de estos convenios) establecen, de forma negociada, "las acciones específicas de carácter social necesarias para la inserción personal, social y laboral". De esta forma, se concreta la idea de que el acceso al empleo y a los programas de inserción debe configurarse como derecho añadido real, y no como una contraprestación por el acceso a las ayudas. Sin embargo, el derecho garantizado no era tanto la inserción como tal, dada la inseguridad en la consecución de los resultados, como el derecho a un apoyo de las instituciones públicas para trabajar en la inclusión social y laboral.

En términos generales, el concepto de doble derecho refleja un paso más en la búsqueda de un equilibrio entre la defensa del derecho incondicional a una garantía de ingresos y los planteamientos que reivindican las políticas de inserción o inclusión. Diversos aspectos permitieron la convergencia en torno a la filosofía del doble derecho.

Por una parte, en el sector contraprestacionista, se avanzó en la aceptación plena de un derecho a un ingreso mínimo por parte de la población. Este avance reflejaba en buena medida el reconocimiento del efecto positivo, sin grandes problemas de dependencia, que la prestación de garantía de ingresos había tenido para la sociedad en Euskadi. La percepción de los riesgos económicos y sociales ligados a la cronificación se había reducido, lo que permitía asumir la idea de desvincular el acceso a la prestación de la aceptación automática de contrapartidas ligadas a la participación en procesos de inserción.

Este cambio también suponía asumir algunas de las limitaciones de la filosofía de la contraprestación. De forma significativa, en la exposición de motivos de la Ley 12/1998 se hablaba de "un tratamiento no totalmente adecuado de la relación entre prestaciones económicas e inserción y, por extensión, entre pobreza y exclusión [...], resultando inadecuados aquellos planteamientos que asimilan automáticamente exclusión social y exclusión económica o bienestar económico y bienestar social”. Una consideración más ajustada de la cuestión aconsejaba, por ello:

Reformular el principio de la inserción en unos términos diferentes, diferenciando el tratamiento de la inserción del que corresponde a las prestaciones económicas necesarias para evitar la pobreza. Así, los convenios de inserción deben orientarse a satisfacer las necesidades de inserción de todas las personas que en la actualidad se encuentran en situación de exclusión, con independencia de que su situación de exclusión se vincule o no con problemáticas de tipo económico.

En paralelo, los sectores técnicos más opuestos a la contraprestación aceptaron dos evidencias que se habían concretado durante el proceso de aplicación de los programas de inserción. Por una parte, se había podido constatar una predisposición muy mayoritaria de la población beneficiaria a participar en los procesos de inserción; por otra, también eran indiscutibles los positivos resultados asociados a la aplicación de los programas de inserción. Aunque no resolvían todos los problemas, ni tenían un efecto amplio ni generalizado, estos programas sí situaban en condiciones comparativamente más favorables a las personas que participaban en ellos. Se consolidó, así, una valoración positiva de las acciones de inserción desarrolladas, unas acciones que eran además bien acogidas por la mayor parte de la población beneficiaria. La perspectiva que ahora se abría era por tanto contribuir a consolidar, por vía de derecho, el acceso a estos procesos orientados a la inserción. 
En la práctica, esta dinámica supuso aceptar las razones y argumentos que subyacían a dos aproximaciones en el diseño de los programas de garantía de ingresos que resultaban, a priori, en gran medida contradictorias. Reflejan, por tanto, un cierto reconocimiento mutuo de la importancia del trabajo en las dos direcciones, definiendo las bases de lo que podría ser un nuevo consenso o paradigma en el diseño de los programas de rentas mínimas.

En definitiva, en la forma en que se introduzco en el Euskadi, tras la aprobación de la Ley 12/1998, el modelo de doble derecho trataba de hacer compatibles dos lógicas diferenciadas: la que defendía la necesidad de una prestación de 'última red' para hacer efectivos unos ingresos mínimos, no sometida a principios de contraprestación, y aquella que sostenía que era necesaria una política de inserción que previniera la cronificación.

Es importante precisar, sin embargo, que el modelo vasco de doble derecho es diferente del que propone el establecimiento de dos derechos separados y no interrelacionados (en algunos casos, defendiendo que el acceso a tales derechos no quede sujeto a ningún tipo de condición asociada). En esta aproximación alternativa no se estaría hablando, en realidad, de doble derecho, sino de derechos diferenciados y no interrelacionados. El modelo que se configuró en la legislación vasca contra la exclusión social se caracterizaba más, por tanto, por la configuración de dos derechos interrelacionados para personas en riesgo de exclusión que por la de dos tipos separados de derechos.

Uno de los rasgos asociados a este planteamiento, en su vertiente relativa a la inserción social es una cierta concepción de derecho 'obligado'. Así lo recogía la exposición de motivos de la Ley 12/1998:
A tales fines, la ley prevé para los beneficiarios del ingreso mínimo de inserción su necesaria participación en programas y acciones de inserción en base a convenios de contenido negociado. Este compromiso representa para el individuo su derecho a tomar parte activa en la vida social, su inserción en el sistema y no su dependencia del mismo. Asimismo, pone de relieve la necesidad que la sociedad tiene de su participación, garantizando, en suma, la igualdad de las partes intervinientes.

De esta forma, persistía la idea de aceptación de aquellas obligaciones que reflejaran una perspectiva de compromiso entre las partes. La Ley contra la Exclusión Social incluía así, para los titulares del ingreso mínimo de inserción, la obligación de negociar, suscribir y cumplir un convenio de inserción con la Administración, en el que se establecían una serie de compromisos. Además, el desarrollo normativo de la Ley $12 / 1988$ obligaba a no rechazar una oferta de empleo adecuado, entendido éste en los términos previstos en la normativa correspondiente y en los del convenio de inserción, en su caso.
De esta forma, el derecho a la inserción se estableció como un tipo de derecho que, como otros (el relativo a la educación, por ejemplo), pudiera entenderse en ciertas circunstancias como de uso obligatorio (pero no por ello menos derecho). Conviene precisar sin embargo que, en la concepción original de la Ley $12 / 1998$, la obligación no se vinculaba al contenido del propio instrumento (el convenio de inserción), sino al principio de negociación del convenio y el compromiso de cumplimiento de los elementos acordados. La idea de negociación entre partes que trabajan por un mismo fin, la inserción, era relevante en esta concepción de las rentas mínimas.

Sin perjuicio del planteamiento negociado de las obligaciones ligadas al convenio de inserción, la normativa preveía algunas excepciones, huyendo de una extensión generalizada en la obligación del convenio de inserción. El acceso a estos convenios quedaba abierto además a todas las personas que, por encontrarse en situación o riesgo de exclusión, fueran susceptibles de ser destinatarias del apoyo, fueran o no titulares de las rentas mínimas.

Esto abría, desde una perspectiva universalista, el derecho a la inserción a colectivos no dependientes de la prestación económica. Se trataba así de un derecho de vocación universal, un aspecto que resulta muy relevante en la aproximación de la Ley contra la Exclusión Social. En el Decreto 1/2000, de 11 de enero, por el que se regulan los convenios de inserción, se establece de hecho que:

En tanto que programa individualizado de intervención, en su vertiente de exclusión social y laboral, el ejercicio del derecho a la activación y a la inclusión social y laboral debería en realidad plantearse como un derecho de contenido universal susceptible de beneficiar a cualquier persona que se vea privada de él, con independencia del acceso o no a prestaciones de garantía de ingresos.

El doble derecho constituía así una aproximación abierta, y no culpabilizadora, a los procesos de inserción. Se complementaba con la reafirmación en la oposición a formas de contraprestación laboral, el apoyo a fórmulas complementarias de integración laboral (programa Auzolan y empresas de inserción) y la introducción de una nueva medida, los estímulos al empleo.

\subsection{Los estímulos al empleo}

Como novedad relevante de cara al futuro, la Ley 12/1998 introducía un nuevo mecanismo de incentivación positiva a la inserción laboral. Se trataba del sistema de estímulos al empleo por el que una parte significativa de los ingresos por trabajo se deducen a la hora de establecer la cuantía de la prestación. De esta forma, la Ley 12/1998 “prevé que podrán quedar excluidos del cómputo de recursos determinados porcentajes de ingresos procedentes 
del trabajo por cuenta propia o ajena. Este instrumento debe constituir un aspecto fundamental de la política de apoyo a la inserción laboral de las personas en situación de exclusión".

El sistema de estímulos al empleo en Euskadi tenía en cuenta de esta forma que, en la relación entre políticas de activación/inserción y prestaciones de garantía de ingresos, un aspecto central es el relativo a "la compatibilidad de la percepción de las prestaciones con las rentas de trabajo". Se trata de una cuestión de especial relevancia en una sociedad ya entonces caracterizada por la importancia de la temporalidad en el empleo $\mathrm{y}$, de manera creciente, de los bajos salarios.

El sistema de estímulos al empleo constituye, sin duda, una vía para garantizar un complemento a la población trabajadora con bajos salarios o ingresos por autoempleo, permitiendo que las personas perceptoras de rentas mínimas rentabilicen el acceso al empleo, compatibilizando los ingresos por trabajo con los de una parte de la prestación. En su origen, sin embargo, la necesidad de dar una solución al problema de los bajos salarios no era el elemento determinante. Los estímulos al empleo se consideraron principalmente para otra función decisiva: permitir que las diferencias de ingresos entre una situación de no ocupación y de empleo siguieran existiendo y resultaran significativas, incluso en el supuesto de establecimiento de prestaciones de cuantía importante, equivalentes 0 superiores a los del salario mínimo interprofesional (tal y como, de hecho, ocurre en Euskadi con el sistema de garantía de ingresos).

De esta forma, el sistema de bonificación al empleo en el modelo de rentas mínimas de Euskadi se planteó, sobre todo, como un mecanismo orientado a fortalecer en toda situación el interés económico por el trabajo ${ }^{1}$. La diferencia de ingresos, en una situación de no ocupación y empleo, resulta importante en el sistema vasco, aspecto que se vincula no sólo a la bonificación al empleo, sino a la posibilidad de acceso de la población ocupada con bajos ingresos a la prestación complementaria de vivienda. En este sentido, el sistema de bonificación al empleo se perfila como una medida de incentivación positiva frente a las alternativas que buscan desincentivar el acceso a las prestaciones a través de una reducción de sus cuantías.

No obstante, la existencia de bajos salarios ya era una realidad, tanto a finales de los ochenta como de los noventa, cuando se consolidó legalmente el sistema de estímulos al empleo. Los trabajadores pobres

${ }^{1}$ Con esa orientación, la propuesta ya se planteó en los mismos orígenes del sistema de garantía de ingresos en Euskadi. En realidad, la Ley 2/1990 anticipaba esta orientación cuando señalaba que "al objeto de motivar el empleo y que la percepción de la prestación prevista en la presente ley no comporte actividades disuasivas frente al mismo, el Gobierno Vasco podrá establecer reglamentariamente otras ayudas complementarias destinadas a hogares con ingresos procedentes de sueldos y salarios". no son un fenómeno propio de la situación social actual, ni siquiera de las fases de mayor bonanza de la sociedad industrial y postindustrial. Aunque la política de estímulos al empleo es parte de la solución al problema de los bajos salarios, es evidente que se requieren medidas que hagan posible que el acceso al empleo permita situar a las personas al margen del sistema de rentas mínimas. La solución a este asunto entra de lleno, sin embargo, en el ámbito de la política económica y laboral general. El problema fundamental para la política de rentas mínimas sigue siendo determinar la mejor formar de garantizar un marco adecuado de incentivos al empleo y proteger, al mismo tiempo, a la población trabajadora con ingresos insuficientes por trabajo. La aproximación de la Ley contra la Exclusión Social asumía, en cualquier caso, que las políticas que pretendan combinar activación/ inserción con garantía de ingresos deben incorporar medidas que permitan "compatibilizar el empleo con las rentas mínimas”.

Las acciones de bonificación al empleo se han convertido, a partir de 1998, en un elemento central de la política de rentas mínimas desarrollada en el País Vasco. En su planteamiento inicial, la aproximación planteaba además una concepción estructural del estímulo al empleo, sin introducir límites temporales al posible complemento. Es interesante señalar que, en la concepción señalada, el sistema vasco se fue alejando de forma progresiva del modelo de renta mínima de inserción definido en Francia. Este modelo también acabó siendo abandonado en ese país en favor de mecanismos, como el Revenu de Solidarité Active (RSA) o la Prime d'Activité, que tienen muchos más puntos en común con la aproximación que se diseñó en la Ley vasca contra la Exclusión Social.

\section{La política de activación}

Durante al menos una década, los principios de la Ley contra la Exclusión Social orientarán la aplicación de la política de garantía de ingresos en Euskadi. Pero desde su misma aprobación se van poniendo las bases de un nuevo replanteamiento, ligado a la progresiva extensión en Europa del paradigma de la activación. Se trata de una línea, afianzada a partir de 2008 , en la que vuelve a concebirse la prestación de garantía de ingresos como un instrumento principalmente orientado a la inclusión, ahora mucho más claramente vinculada al ámbito laboral. De forma llamativa, la izquierda política y sindical, así como los grupos del tercer sector social, contribuyen de manera decisiva a esta reorientación.

\subsection{La Carta Social}

El efecto de la movilización social que confluyó, a lo largo de los años noventa, en la iniciativa legislativa popular para una Carta de Derechos Sociales tuvo algunas importantes consecuencias sobre el tratamiento de la condicionalidad. En 
particular, supuso recuperar en parte el principio de contraprestación.

En el apartado relativo a la renta básica, llamada a sustituir al ingreso mínimo de inserción, la Ley 10/2000, de 27 de diciembre, de Carta de Derechos Sociales, volvía a situar la concepción de la prestación en unos términos más cercanos a los que había prefijado el Revenu Minimum d'Insertion francés. De esta forma, la nueva ley ligaba el acceso a la prestación de garantía de ingresos a la carencia de "recursos económicos suficientes para poder hacer frente a las necesidades básicas y a las derivadas de un proceso de inserción social y laboral". Y vinculaba la duración de la prestación a la subsanación de "las causas que dieron origen a la falta de cobertura de necesidades básicas o se logre la inserción social”, definida como la finalidad principal de la ley. El derecho a la inserción sociolaboral se asociaba de forma directa, además, a la "participación obligada en convenios de inserción”. La norma llegaba a contemplar, como requisito necesario para acceder a la prestación, "la certificación del estado de necesidad expedida [...] por parte de los servicios sociales de base".

Aunque parte del lenguaje utilizado procedía de la Ley $12 / 1998$, este conjunto de preceptos chocaba de frente con el planteamiento del doble derecho. No en vano, la concepción de la Ley contra la Exclusión Social establecía que la garantía del derecho a la protección económica era independiente de unas acciones para la inclusión cuya financiación correspondía a las instituciones encargadas de diseñar los programas de intervención (y no a la propia población beneficiaria de la prestación, como se sugería en la definición de la nueva renta básica).

Es cierto que el contenido de la iniciativa legislativa popular no planteaba de forma estricta el marco finalmente aprobado, pero es indudable su contribución a recuperar la contraprestación. En su artículo 9, relativo a las obligaciones ligadas al acceso a la renta básica, la iniciativa planteaba en concreto que los beneficiarios de la renta básica "estarán obligados a suscribir un acuerdo negociado con la Administración, por medio del cual se establecerá la aportación o contrapartida social que deberán realizar en beneficio de la sociedad”. Apenas matizaba que la contrapartida planteada será "de carácter social y comunitario sin que tengan en ningún caso naturaleza laboral”.

De forma paradójica, la falta de desarrollo normativo de la nueva Ley 10/2000, que de facto derogaba parte de la Ley contra la Exclusión, hizo que prevalecieran los decretos de desarrollo de la ley de 1998, nunca reformados en profundidad hasta la aprobación, en 2010, de las normas de desarrollo reglamentario de la Ley $18 / 2008$, para la Garantía de Ingresos y para la Inclusión Social. De esta forma, la concepción del doble derecho, y la filosofía que la inspiraba, se mantuvo como referencia orientadora en la aplicación de la política de garantía de ingresos en Euskadi.
4.2. La Ley $18 / 2008$, para la Garantía de Ingresos y para la Inclusión Social

La aprobación de la Ley 18/2008, para la Garantía de Ingresos y para la Inclusión Social, promovida por Eusko Alkartasuna, supone el verdadero hito inicial en la reorientación de la política vasca de garantía de ingresos hacia la activación. El objetivo de la nueva ley es profundizar en esa dimensión de activación de las políticas de garantía de ingresos y en la rentabilización del empleo. A tales efectos, pretende establecer "los principios de funcionamiento y las bases estructurales del Sistema Vasco de Garantía de Ingresos e Inclusión Social, capaces, por su dinamismo y flexibilidad, de promover el aumento progresivo de la cobertura resultante de la aplicación combinada de una pluralidad de instrumentos económicos, sociales y laborales orientados a la inclusión social".

La nueva ley consolida la visión, ya presente en la Carta Social, del ingreso mínimo como instrumento ligado no sólo a la cobertura de las necesidades básicas, sino también a hacer frente a los gastos orientados al proceso de inclusión social. Define así la nueva renta de garantía de ingresos como una prestación "dirigida a las personas integradas en una unidad de convivencia que no disponga de ingresos suficientes para hacer frente tanto a los gastos asociados a las necesidades básicas como a los gastos derivados de un proceso de inclusión social”.

La aproximación de la Ley 18/2008 mantiene el principio del doble derecho. De esta forma, junto con el derecho a las prestaciones económicas, se plantea el derecho a "los instrumentos orientados a prevenir el riesgo de exclusión, a paliar situaciones de exclusión personal, social y laboral, y a facilitar la inclusión de quienes carezcan de los recursos personales, sociales o económicos suficientes para el ejercicio efectivo de los derechos sociales de ciudadanía". Pero la orientación a la promoción laboral es mucho más nítida. En la exposición de motivos de la nueva ley se señala, en este sentido, que la asunción del reto de la activación en las políticas contra la exclusión social en Euskadi se vincula con "el reconocimiento de un derecho específico a recibir de la Administración los apoyos necesarios para la inclusión sociolaboral”.

La norma insiste, por otra parte, en la idea de reciprocidad al considerar la dimensión obligada del convenio de inserción. Así, se habla del "derecho a recibir apoyos personalizados para la inclusión laboral y social, mediante la participación obligada en un convenio de inclusión, poniéndose así en práctica el principio de reciprocidad entre la Administración y el ciudadano o la ciudadana en situación de exclusión”.

La nueva ley también mantiene el mecanismo de estímulos al empleo. Lo revisa, sin embargo, para darle un contenido meramente temporal, un cambio sustancial respecto a lo establecido en la Ley contra la Exclusión Social. 


\subsection{La Ley 4/2011, de modificación de la Ley para la} Garantía de Ingresos y para la Inclusión Social

La Ley 4/2011, de modificación de la Ley para la Garantía de Ingresos y para la Inclusión Social, basada principalmente en un acuerdo entre el Partido Socialista de Euskadi y el Partido Popular, se presenta como "una reformulación del modelo anterior”. La principal expresión de esta reformulación es el traspaso de la gestión de la renta de garantía de inserción de los servicios sociales a los de empleo. Una vez materializada la transferencia de las políticas activas, se hace posible consolidar la orientación explícita a la inserción laboral introducida en la Ley 18/2008, dando así un nuevo paso adelante hacia las políticas de activación y de empleabilidad. En la concepción de la Ley 4/2011, la materialización de la transferencia de las políticas activas de empleo dota a la administración vasca "de capacidad propia para contribuir al desarrollo del derecho al empleo, estable y de calidad, y favorecer la configuración de un mercado de trabajo que contribuya de forma eficiente a garantizar la empleabilidad de las personas trabajadoras [...] a través de la gestión de las políticas de empleo".

Esta filosofía es la base de creación de Lanbide. Según la exposición de motivos de la Ley 4/2011, "el ejercicio competencial que en materia de activación laboral puede desarrollar la Comunidad Autónoma de Euskadi, y la necesidad de llevarla a cabo en este ámbito de la garantía de ingresos y la inclusión, aconsejan en este momento dar traslado de esta política al dispositivo de empleo". Eso se traduce en "la asunción desde el Gobierno Vasco y, en particular, a través de Lanbide Servicio Vasco de Empleo, de las competencias relacionadas con la tramitación y resolución de las prestaciones económicas de derecho [...], así como de la elaboración, propuesta, negociación, suscripción y seguimiento de los convenios de inclusión", definidos ahora como de inclusión activa. Con esta aproximación, los convenios de inserción se perfilan como la expresión práctica de la acción orientada a activación y la promoción laboral.

La nueva orientación se considera fundamental "en la consecución de la implementación de los principios básicos del nuevo modelo, directamente asociados a la estrategia integral de inclusión activa, que articula, junto con las medidas orientadas a la garantía de ingresos y a la inclusión social, otras medidas orientadas a la inclusión laboral efectiva". Entre estas medidas, la Ley menciona la disponibilidad activa para el trabajo o la formación profesional, y a la rentabilización del empleo, "con el fin de que la inclusión laboral constituya, en todos los casos, una opción atractiva o rentable". Esta estrategia de mejora laboral se plantea tanto para las personas desempleadas como para las inactivas e incluso las actualmente ocupadas "en una situación de precariedad laboral asociada a la inestabilidad en el empleo 0 a los bajos niveles salariales". En estos casos, la legislación se plantea como objetivo favorecer "la aplicación de una estrategia de flexiguridad orientada a facilitar la progresión hacia mejores empleos, mediante estrategias globales de aprendizaje permanente que doten a las personas de las capacidades necesarias para progresar en su vida laboral garantizando su adaptabilidad y empleabilidad continuas".

\subsection{Los puntos centrales de la nueva concepción}

En la forma en que acaba siendo definido entre 2008 y 2011, tres son los aspectos centrales del modelo que pretende superar los preceptos de la Ley contra la Exclusión Social. El primero de ellos es la consagración de los principios de activación y de centralidad del empleo en la política de garantía de ingresos. La nueva orientación asume, en este sentido, una estrategia, dominante en Europa, que impulsa la activación de la población en edad activa y medidas de promoción personal que pretenden facilitar la inserción laboral. En esa línea, se afirma la idea de que las políticas sociales aplicadas en Euskadi -y en particular las políticas contra la exclusión social- "han asumido desde su creación el reto de la activación". La reforma Hartz alemana se presenta, en este contexto, como el referente dominante, con una visión en la que el ingreso mínimo aparece como una prestación orientada a la activación laboral.

La prioridad del empleo resulta evidente en esta visión de las rentas mínimas. La exposición de motivos de la Ley 18/2008 afirma, en este sentido, su papel como herramienta de inclusión social:
El modelo se basa en el reconocimiento del papel del empleo como herramienta básica para la inclusión en nuestra sociedad, y en la necesidad de reducir tanto las tasas de desempleo que se registran entre los grupos más desfavorecidos como las elevadas tasas de inactividad de determinados colectivos. Por ello [...] subyace a la regulación el objetivo general de facilitar la incorporación al mercado de trabajo del mayor número posible de personas $\mathrm{y}$, en coherencia con ese objetivo, de devolver al mercado de trabajo su capacidad como factor de inclusión social.

Esto viene acompañado de una muy superior insistencia en la disponibilidad para el trabajo, afirmándose con respecto a las personas beneficiarias de la renta de garantía de ingresos el "compromiso de permanecer inscritas ininterrumpidamente como demandantes de empleo, de no rechazar un empleo adecuado de acuerdo con la legislación vigente, de no darse de baja voluntaria ni definitiva ni temporal del empleo y de no acogerse a una situación de excedencia laboral sin causa extrema justificada". La reforma de 2011 acentúa esta dirección de la política de garantía de ingresos al contemplar los motivos de extinción de la prestación. Se reduce así de tres a uno el número de casos posibles de rechazo, sin causa justificada, de un empleo adecuado. 
Un segundo elemento fundamental del nuevo modelo, ligado al anterior, es el paso de la gestión de las prestaciones económicas a Lanbide. A través de Lanbide, la idea de la Ley 4/2011 es "reforzar la asociación directa entre ambos elementos, la prestación y el convenio de inclusión, configurándose éste como un instrumento orientado a la inclusión activa”. El traspaso de la renta de garantía de ingresos a Lanbide concreta el paso de una prestación para la "inserción social" a una orientada a la "activación laboral".

Aunque esta línea no se materializa hasta 2011, tras la transferencia de las políticas activas, las previsiones que llevan a Lanbide ya estaban contenidas en la Ley 18/2008. Al hablar de sistemas de gestión en su exposición de motivos, esta ley adelantaba la preferencia por los servicios de empleo, al señalar en relación con las formas de gestión "que, si bien en la actualidad se incardinan en los servicios sociales", éstas quedarían asociadas a "los servicios de empleo, en el futuro" (sin perjuicio de contemplar igualmente que pudieran “enmarcarse, total o parcialmente, en otros ámbitos de actuación”).

A pesar de ello, en virtud de las excepciones previstas en la legislación, Lanbide sigue teniendo que atender, a través de la renta de garantía de ingresos, a colectivos que no son objeto de actuaciones para la inserción laboral. Dada la situación del mercado laboral, además, la renta de garantía de ingresos cumple un papel en los procesos de inserción social, que se acentúa ante las dificultades observadas en los procesos de activación e inserción laboral. Ello sigue poniendo de manifiesto una realidad mucho más compleja que la que era previsible antes del proceso de transferencias.

Un tercer punto en la nueva aproximación es el paso de la dimensión estructural del sistema de incentivos al empleo a su aplicación con límites temporales. Se trata quizás del cambio más contradictorio en la nueva aproximación, en especial si se tiene en cuenta la importancia que la nueva legislación atribuye al papel de los bajos salarios en la pobreza y la necesidad de mejorar el atractivo de los empleos peor remunerados ${ }^{2}$. Pero la reforma refleja, en cierta forma, las fuertes reticencias mostradas por ciertos sectores sindicales y de partidos de la izquierda ante los complementos a los bajos salarios.

${ }^{2}$ En la exposición de motivos de la Ley $18 / 2008$, se establece la necesidad de responder "con soluciones específicas a una situación crecientemente observada, a saber, el hecho de que la prestación se conceda, cada vez más, como una ayuda orientada a complementar un bajo nivel de ingresos y tenga por destinatarias a personas cuyas dificultades son de naturaleza exclusivamente económica y no precisan, por tanto, de apoyos especializados para la inclusión”. Señala, por otra parte, la apuesta por "un modelo que, considerando el empleo como la mejor vía de inclusión, consiga hacer atractiva la incorporación al mercado laboral incluso para acceder a un empleo de bajo nivel salarial" y la necesidad de desarrollar estas medidas "en un contexto como el vasco, en el que la cada vez menor diferencia existente entre la cuantía de la renta básica y el salario mínimo interprofesional podría tender a generar distorsiones en la demanda de estas prestaciones y en el funcionamiento del mercado de trabajo".
Los cambios señalados vienen acompañados de un endurecimiento en el tratamiento de las obligaciones asociadas al acceso a las prestaciones económicas. Así, se establecen nuevas obligaciones, orientadas a consolidar ciertas pautas de comportamiento, por ejemplo, la que exige "administrar responsablemente los recursos disponibles con el fin de evitar el agravamiento de la situación económica o de la situación de exclusión", una vía que lleva a plantear la posibilidad de control de los gastos de la población beneficiaria.

Aunque nunca se ha aplicado de facto, la reforma de la Ley 4/2011 llega incluso a romper el tabú de la contraprestación laboral, al plantear la posibilidad de recurrir a los trabajos de utilidad pública. De esta forma, la última legislación introduce, con apenas algunas excepciones, un nuevo apartado 19.1.i bis que plantea como obligación "mantenerse tanto la persona titular como los miembros de su unidad de convivencia que se encuentren en edad laboral disponibles para la realización de trabajos en beneficio de la comunidad cuando de forma extraordinaria sea requerido por la Administración, a través de organizaciones de acción voluntaria del territorio".

\section{Conclusión}

El debate sobre la condicionalidad en Euskadi es inseparable del contexto en el que surgieron las políticas de garantía de ingresos a finales de los años ochenta. Éste se vio definido tanto por la apuesta francesa por la renta mínima de inserción como por la oposición del Estado a las iniciativas autonómicas, ejemplificada en el discurso de la caña y el pez. Este contexto condicionó el enfoque regulador de las rentas mínimas desde sus orígenes, contribuyendo a la introducción del principio de contraprestación en las primeras normativas.

Sin embargo, el debate desarrollado en Euskadi en torno a la condicionalidad, y a otros aspectos de las políticas de rentas mínimas, en ningún caso fue una mera traslación del existente en otros países, sino que se caracterizó por la búsqueda de soluciones propias. Además de la influencia del Revenu Minimum d'Insertion francés, en el caso vasco también resultó relevante la aproximación británica, tanto en lo relativo a las medidas de bonificación al empleo como a la política de ayudas complementarias a la renta mínima, recogidas en las llamadas ayudas de emergencia social. Esta realidad contribuyó a configurar un modelo original.

En la dimensión relativa a la condicionalidad, tras un periodo marcado por la preocupación por la contraprestación, la máxima expresión de esta originalidad fue la introducción del principio del doble derecho: el derecho a una prestación de garantía de ingresos, que incluyó luego un complemento de vivienda, completado con un derecho paralelo a un apoyo para la inserción social 
y laboral. Este modelo de doble derecho perfilaba una aproximación que, sin eliminar por completo la condicionalidad, en especial en términos de obligación de negociar un convenio de inserción o de aceptar un empleo adecuado, rechazaba sin embargo limitar el derecho básico a unos ingresos mínimos para la población en situación de necesidad. De esta forma, el modelo se alejaba de una concepción punitiva de contraprestación.

En gran parte, este perfil peculiar del sistema vasco de garantía de ingresos es el reflejo de un aspecto de la dinámica de configuración del modelo vasco en sus fases iniciales: el duradero debate e intercambio de puntos de vista entre la esfera política y técnica. Una de las implicaciones de ese debate fue la introducción de contrapesos en la orientación ligada a la contraprestación.

Desde la aprobación de la Carta Social hasta la última reforma destacada de la política de garantía de ingresos en Euskadi, la concretada en la Ley 4/2011, el reforzamiento de la condicionalidad ha ido ganando peso de nuevo. Esta tendencia se ha manifestado en tres grandes líneas. En primer lugar, en la recuperación del vínculo conceptual entre el derecho a la prestación de garantía de ingresos y la inserción/inclusión. Aunque se mantiene en la dimensión formal el principio del doble derecho, han recuperado relevancia las ideas de reciprocidad y de contrapartida en el acceso a las prestaciones.

Un segundo punto se relaciona con la aplicación del principio de activación en la concepción de la acción para la inserción. Además de la dimensión promocional (orientación, formación), la activación viene asociada a la exigencia de la disponibilidad para el empleo o de la aceptación más o menos estricta de formas de empleo adecuado. En la reforma de 2011, se introduce incluso la posibilidad de la aplicación de la contraprestación laboral, mediante trabajos de utilidad pública. Las políticas de activación pretenden, por esta vía, mantener a la población en una situación efectiva de actividad y, en su caso, exigir formas de compromiso laboral. Esta concepción de la activación tiene una clara dimensión obligacionista que, en algunos aspectos, busca condicionar las pautas de actuación de la población beneficiaria.

Un tercer aspecto asociado es, de hecho, la introducción de formas más estrictas de control de los propios procesos de comportamiento, por ejemplo, a través del control de los tipos de gasto realizados por la población beneficiara de la renta de garantía de ingresos.
A pesar de ello, algunos elementos centrales de la reforma de 1998 han conseguido sobrevivir en las décadas siguientes, en particular la idea de un derecho esencial a una garantía de ingresos. Este objetivo ha logrado consolidarse en la gestión de las rentas mínimas en Euskadi, tal y como ha podido observarse durante la pasada crisis, un periodo en el que la efectividad del derecho a una garantía de ingresos llegó a convertirse en uno de los aspectos centrales del debate sobre las políticas sociales. En cierta forma, la condicionalidad ha constituido un referente para reforzar las posibilidades de control e intervención de ciertos colectivos, pero no ha conseguido poner en tela de juicio el principio básico de un derecho a unos ingresos mínimos para toda la población.

Se trata de un rasgo que fue igualmente determinante en las fases iniciales de implantación de las políticas de rentas mínimas en Euskadi, por relevantes que llegaran a resultar por entonces las obligaciones ligadas a la contraprestación. También en aquel periodo, el principal objetivo de la intervención fue garantizar unos ingresos mínimos a la población, en un contexto de debacle industrial sin precedentes para uno de los territorios con mayor protagonismo en el desarrollo histórico de la industria en Europa.

Es importante señalar por tanto la permanencia, más allá de los cambios conceptuales sobre inserción y activación, de una clara aceptación del acceso al ingreso mínimo como elemento principal de las políticas de garantía de ingresos. Se trata de una realidad que no está realmente, o predominantemente, condicionada por la consolidación paralela del principio y del proceso de activación. Se mantiene así en gran medida vigente la concepción de la política de rentas mínimas expresada en la exposición de motivos de la Ley 2/1990, "basada en el respeto a las personas y en la creencia de que la marginación no responde a razones intrínsecas, sino a factores externos que les imposibilitan salir de la situación en que se encuentran si los ciudadanos más favorecidos no ejercitan la solidaridad social”.

Esta concepción se ha mantenido en la aplicación de la política de garantía de ingresos en Euskadi desde sus inicios. Y a ella se debe la impresión de continuidad en la aplicación de unas políticas cuyos fundamentos doctrinales han resultado en realidad muy variables. En cierta forma, la aceptación esencial del derecho a una garantía de ingresos es la que ha servido históricamente de contrapeso en Euskadi a los planteamientos más duros ligados a la contraprestación o la activación. 
FRANCIA (1988): “Loi n88-1088 du 1 décembre 1988 relative au revenu minimum d'insertion" [rhttps://www.legifrance.gouv.fr/affichTexte.do ;jsessionid=C9DB8CCCE095ECEDF1DBDE6DCB3 BC892.tpdila16v_2?cidTexte=JORFTEXTo00000 875188\&dateTexte $=20041025>$ ].

GOBIERNO VASCO (1989): “Orden de 5 de octubre de 1989, del Consejero de Presidencia, Justicia y Desarrollo Autonómico, por la que se dispone la publicación del Acuerdo Marco para el Desarrollo del Plan Extraordinario 'Euskadi en la Europa de 1993', Boletín Oficial del País Vasco, $n^{\circ}$ 196, 18-10-1989 ['https:// www.euskadi.eus/y22-bopv/es/bopv2/ datos/1989/10/8902790a.shtml〉].

PAÍS VASCO (2011): “Ley 4/2011, de 24 de noviembre, de modificación de la Ley para la Garantía de Ingresos y para la Inclusión Social", Boletín Oficial del País Vasco, n- 233, 12-12-11 [<https://www.euskadi.eus/y22-bopv/es/ bopv2/datos/2011/12/1105924a.shtmls].

- (2008): "Ley 18/2008, de 23 de diciembre, para la Garantía de Ingresos y para la Inclusión Social", Boletín Oficial del País Vasco, n250, 31-12-08, págs. 32.729-32.804 [khttps:// www.euskadi.eus/y22-bopv/es/bopv2/ datos/2008/12/0807235a.shtmlı].

- (2002): “Decreto 199/2002, de 30 de julio, por el que se articula el Programa Auzolan, para la Inserción Laboral de las personas en situación o riesgo de exclusión", Boletín Oficial del País Vasco, no 0 174, 13-9-2, págs. 16.496-16.515 [<https:// www.euskadi.eus/y22-bopv/es/bopv2/ datos/2002/09/0205129a.shtmls].

- (2000): "Decreto 1/2000, de 11 de enero, por el que se regulan los Convenios de Inserción", Boletín
Oficial del País Vasco, ํํ20, 31-1-00, págs. 1.800-1.815 [<https://www.euskadi.eus/y22bopv/es/bopv2/datos/2000/01/0000408a. shtml>].

- (2000): "Ley 10/2000, de 27 de diciembre, de Carta de Derechos Sociales", Boletín Oficial del País Vasco, no 249, 30-12-00, págs. 23.377-23.379 [hhttps://www.euskadi.eus/y22-bopv/es/ bopv2/datos/2000/12/0005881a.shtml/].

- (1998): “Ley 12/1998, de 22 de mayo, contra la Exclusión Social”, Boletín Oficial del País Vasco, $\mathrm{n}$ 은 105, 8-6-98, págs. 10.467-10.506 [khttps:// www.euskadi.eus/y22-bopv/es/bopv2/ datos/1998/06/9802519a.shtmls].

- (1990): “Ley 2/1990, de 3 de mayo, de Ingreso Mínimo de Inserción", Boletín Oficial del País Vasco, no 106, 30-5-9o, págs. 5.107-5.117 [rhttps:// www.euskadi.eus/y22-bopv/es/bopv2/ datos/1990/05/9001683a.shtml'].

- (1989): “Decreto 38/89, de 28 de febrero, por el que se regula la concesión del Ingreso Mínimo Familiar”, Boletín Oficial del País Vasco, no 44, 6-3-89, págs. 1.362-1.369 [rhttps:// www.euskadi.eus/y22-bopv/es/bopv2/ datos/1989/03/8900574a.shtmls].

PARLAMENTO VASCO (1997): “Proposición de ley para una Carta de Derechos Sociales", Boletín Oficial del Parlamento Vasco, V legislatura, no 142, 5-12-97, págs. 12.171-12.175 [khttp:// www.legebiltzarra.eus/BASIS/izaro/webx/ cm_bopvc/DDW?W=boc_clave $=\% 2705090204$ $000319971205012171 \% 27 \% 26 \mathrm{M}=1 \% 26 \mathrm{~K}=050$ $90204000319971205012171 \% 26 \mathrm{R}=\mathrm{N} \% 26 \mathrm{U}=20$ $\% 26 \mathrm{PCU}=1\rangle]$. 